\title{
Cross-Sector Collaboration and Information Integration in Local Government One-Stop Services Centers: The Experiences and Lessons from a Case Study in China
}

\author{
Nan Zhang \\ School of Public Policy \& \\ Management, Tsinghua University, \\ Beijing, China \\ nanzhang@tsinghua.edu.cn
}

\author{
Zhikui Lu \\ School of Public Policy, Xiamen \\ University, Xiamen, China \\ zklu@xmu.edu.cn
}

\author{
Yunyun Shou \\ School of Public Policy \& \\ Management, Tsinghua University, \\ Beijing, China \\ 1911148503@qq.com
}

\begin{abstract}
The government of China is experiencing a transformation from the control-oriented government to a service-oriented government. And the one-stop service centers established by local governments at all levels are exactly the practice aiming to integrate administrative resources and provide citizen with more convenient services. E-government implementation and public information integration is generally looked as a driving force to promote the one-stop service transformation. However, the new pattern of one-stop service and related information integration have been impacted by benefits division and power structure of the traditional sectors. Based on the Bryson's framework in collaborative public administration research, the study conducted a case analysis of administrative structure and operation process of an information integration project, named "Quan-chengdai-ban", in one-stop service centers in Beijing, attempting to reveal the key determinants of crosssector collaboration and information integration in the local governments in China.
\end{abstract}

\section{Introduction}

Collaboration has always been one of the most important issues in the research area of contemporary public management. Since today's public managers operate in collaborative settings every day [1], public administration enters into a new generation in great need of more cross-sector collaborations [19]. Crosssector collaboration is increasingly assumed to be a series of strategies for dealing with most of difficult public challenges in current society, such as transboundary natural resources management, regional economic development, poverty, climate change and environmental protection, natural disaster, emergency management and so on $[1,19,30]$. The Public managers often find themselves facilitating and operating in multi-organizational networked arrangements to solve such inter-connected problems which cannot be solved easily by single sector [30]. The future of public administration to a certain extent will be the mode of cross-sector collaborative public management.

Collaboration is also important to organization governance and service delivery of Chinese local government. The government of China is experiencing a transformation from the control-oriented government to a service-oriented government [42]. And the onestop service centers established by local governments at all levels are exactly the practice aiming to integrate administrative resources and provide citizen with more convenient services [42, 45]. E-government implementation and public information integration is generally looked as a driving force to promote the onestop service transformation [26,44]. However, the new pattern of one-stop service and related information integration has been impacted by benefits division and power structure of the traditional sectors. Handling the challenge mentioned above properly and build a new governance structure around public service delivery is crucial to determine the sustainability of one-stop service centers in the current information age.

Based on Bryson et al's work [10], we proposed extended theoretical framework and conduct a case study in Chaoyang district of Beijing, focusing on cross-sector collaboration and information integration of their one-stop services centers. The study tries to discuss the information integration issue from the collaboration perspective for filling the research gap between information management and organizational behavior logic in the local government one-stop service center context.

The "Quan-chen-dai-ban” (meaning “one-stop service" in Chinese) project, which is developed and 
implemented by the government agency of Chaoyang District. The project was designed by following the thoughts of workflow management, with users being government employees working in the one-stop service centers of the district's subordinate areas. Through the implementation and application of this customized eGovernment system, this project was aimed at standardizing workflows of daily public services in Chaoyang's subordinate areas, as well as facilitating superior authorities' supervision and assessment. As an ordinary cross-sector information integration project of a local government, the case of this project may, to some extent, reflect some general characteristics of similar projects. The research will be conducted in compliance with a normative case study methodology [43]. In the research process, we laid much emphasis on the diversity of data sources during the collection of evidence and materials. The evidences collected for analysis include: records of several field interviews to key-person of local government, directors of transactional sectors and directors of IT sectors; documents such as announcements, reports, and regulations provided by the government agency during the promotion of the integrative process.

The analysis results show that the stable governance structure can be realized by focusing on the collaborative goal is essential for influencing collaborative performance. For the one-stop services center practices, if the local governments could endow the centers with functions and personnel authority as definite as those of the traditional department, they would have stronger capacity of integrating the administrative service resources dispersed in the different sectors.

\section{Literature review}

Scholars assert that public administration is "repositioning" itself around "models built on the assumptions of institution building, cooperation, productivity, structure, and leadership" [18], and thus public managers now function in "an age of collaboration" $[1,28]$. Cross-sector collaboration has become a common term in the public administration literature. Research on cross-sector collaborations offers a set of findings marked by rapid progress and a continuing focus on knowledge generation. Although cross-sector collaboration has been occurring for quite some time, the amount of research on it has increased significantly over the past decade. Moreover, a number of the most influential theoretical accounts of this phenomenon are focused on specific types of crosssector collaborations and case studies relating to specific policy areas like community policing, public health, education, watershed management, natural resources management, regional economic development planning, metropolitan transportation authority, emergency management and so on.

The study of cross-sector collaborations or collaborative governance is characterized by a surfeit of theories. For example, theoretical answers to the question "why collaborate?" range from authors who propose a single explanation (e.g., resource dependency, exchange and transaction cost or population-ecology) to authors who list as many as fourteen different ones. While identifying these diverse theoretical foundations helps us understand crosssector collaborations' multiple dimensions, it is especially important for our purpose here to suggest that a growing convergence of core concepts about collaborative activity can be found in the cross-sector collaborations literature.

\subsection{Driving factors for collaborations}

Alter and Hage proposes four factors that account for collaboration [3]: (1) willingness to cooperate, (2) need for expertise, (3) need for financial resources and sharing of risks, and (4) need for adaptive efficiency. McCaffrey, Faerman, and Hart hypothesizes that collaboration was a function of (1) disposition to collaborate, (2) purposes, issues, and values, (3) social and political organization, and (4) leadership capacity and style [28]. More recent works exhibit a significant commonality of factors reputed to answer the question “why collaborate?” For example, Bryson, Crosby, and Stone identifies the initial conditions for collaboration as (1) environmental factors such as complexity, turbulence, competition, and uncertainty, (2) sector failure by which they mean the degree to which a single effort has failed to solve a public problem, and (3) the presence of direct antecedents of collaboration which are general agreement on the problem, a powerful sponsor or convener, and existing networks [10]. Thompson and Perry's conceptualization lists six antecedent conditions necessary for collaboration [40]: (1) high levels of interdependence, (2) need for resources and risk sharing, (3) resource scarcity, (4) previous history of efforts to collaborate, (5) complex issues, and (6) situations in which each partner has resources that other partners need. Lundin explains cooperation among Swedish public employment service offices by testing the influence of three factors [25]: (1) resource interdependence, (2) goal congruence, and (3) trust. Ansell and Gash in their meta-analysis of 137 cases of collaborative governance "narrowed the critical starting conditions down to three broad variables [4]: imbalances between the resources or power of different stakeholders, the incentives 
stakeholders have to collaborate, and the past history of conflict or cooperation among stakeholders. Emerson, Nabatchi and Balog explains the three dimensions of an integrative framework for collaborative governance [14]: (1) the general system context, (2) the collaborative governance regime (CGR), and (3) its collaborative dynamics and actions. According to leadership, consequential incentives, interdependence, and uncertainty help initiate and set the direction for a collaborative governance regime (CGR). Obviously, a degree of consensus on the core concepts of crosssector collaborations is emerging among scholars.

\subsection{Models construction of collaborations}

Several studies have attempted a theoretical model construction on cross-sector collaboration. More recent models include not just antecedents, process, and outcomes, they also include factors such as institutional design, leadership, number and variety of groups, issues and incentives, structure and governance, and contingencies and constraints [4, 10, 14, 37]. Thomson and Perry provide a multidimensional model of collaboration [40]: the governance dimension, the administration dimension, the autonomy dimension, the mutuality dimension, trust and reciprocity dimension. Bryson et al construct one framework for understanding cross-sector collaboration which includes initial conditions, structure and governance process components, contingencies and constraints affecting process, structure, and governance, outcomes [10]. Ansell and Gash provides a model of collaborative governance which has four broad variables [4]: starting conditions, institutional design, leadership, and collaborative process. Purdy builds a framework for assessing power in collaborative governance processes by juxtaposing the three sources of power with the three arenas for power [37]. Three sources of power that can be used to influence the participants, process design, and content of a collaborative process are particularly useful for understanding interorganizational dynamics: authority, resources, and discursive legitimacy. However, there is still a lack of comprehensive frameworks or models that examine and analyze the collaboration issues across the intergovernmental integration process within the macro-environments of e-governance.

\subsection{The Components of collaborations}

The term "cross-sector collaborations" is often thought of as involving dynamic transactions and political game among governments or between governmental and nongovernmental organizations, in fact, a variety of links are engaged. The heart of any model of cross-sector collaborations is how the actual process is constructed. Also crucial to advancing our understanding of cross-sector collaborations are the specific elements authors include in current research. Of course, empirical research will be necessary to discover which components and which elements of a component contribute positively to cross-sector collaborations. Research is underway, but considerable time will be required before results can be organized into a systematic explanation of cross-sector collaborations. Space in this essay is limited, but it is useful to mention a few preliminary research findings. The studies cited are a very small sampling of the empirical and theoretical work on cross-sector collaborations and information integration. What is needed for furthering this research progress is twofold (1) continued research testing theoretical models and (2) meta-analysis to reformulate theoretical models based on empirical findings.

\subsection{New approaches of Collaborations}

In the latest several years, some authors acknowledge the importance of collaborations from the perspectives of co-production or new governance or governance networks [5, 6, 13, 23, 24, 31, 35]. Osborne et al. argued that co-production is an essential part of a broader framework to provide a new theory for public service delivery a service-dominant approach in the era of the New Public Governance [31], in contrast to the manufacturing-dominant approach of New Public Management (NPM). Kapucu and Garayev define network sustainability as the continuation and/or evolution of network relationships in the absence of triggering factors for network collaboration [23]. Clark et al. investigate how communications advances affect citizens' ability to participate in coproduction of government services based on the 311 systems (nonemergency call centers) [11], and argue that Innovations in how government services are delivered in the 2010s, especially the use of new electronic communications technology, have brought coproduction. Anninck and Lucidarme argue that collaborative networks need to deal with the many uncertainties through relational governance based on trust as a coordination mechanism in a public sector context the typical characteristics of collaborative networks influence the development of trust and obtaining network effectiveness [5]. Pestoff highlights the potential contribution of collective action to making co-production more sustainable in the provision of public services [35]. According to Klijn and Koppenjan's work [24], the governance network perspective distinguishes itself from other, more rational approaches to problem solving, policymaking, 
and service delivery by using the multi-actor nature of interaction settings and the presence of diverging and sometimes conflicting perceptions, objectives, and institutions se the starting point for analysis and management.

In a word, collaboration has become a common and hot topic in the public administration and public management literatures. However, a general model or framework is still in short of. So, when we analyze collaborations, we should be aware of the interactive processes, multi-actors, dynamics, complexity of institutions of collaborations in public administration. This article provides a theoretical framework to advance the understanding of collaboration through integrating extant theories of the current literatures.

\section{Analytic framework}

Categorizing and organizing the prior literature on collaboration, this article presents an analytical framework for understanding cross-sector collaboration and information integration in One-Stop Services Centers around the initial conditions affecting collaboration formation, governing structure, process of collaboration and integration, constraints and contingencies, outcomes, and accountability issues.

\subsection{Initial Conditions}

Inter-organizational systems supporting interagency collaboration must accommodate a wide range of factors from the external environment and participating organizations as part of their design and operation [16]. The literature is clear that conditions present at the outset of cross-sector collaboration can either facilitate or discourage coordination and integration between different agencies. The initial conditions focuses on broad themes related to the general environment in which cross-sector collaborations are embedded, the notion of sector failure as an overlooked precondition for collaboration, and societal change as precondition affecting the formation of cross-sector collaborations [10].

The political, economic, social, and technical context within which cross-sector collaborative relationships have developed, have created a new reality for e-government interoperability and interconnectedness in the digital age. Firstly, political authority frames the environment of public management and shapes decisions by putting "order" into the choices that confront public managers [9]. Secondly, economic environmental complexity and social change affect sector-functional differentiation, organizational structural differentiation and fragmentation of sector responsibility, which make the functions of agencies fallen apart or become fragmented. In this sense it is necessary for the different sectors involved to integrate and work together to form collaborative partnerships and design shared customer interface to provide holistic services to the clients. Facilitative leaders and managers play an important role in facilitating and forming the willingness to develop inter-organizational cooperative relationships.

\subsection{Governing Structure}

Structure is a concept in describing the institutionalization and organization of authority or power relationships, party membership, division of labor, rules and operating procedures. Cross-sector collaborative relationships analysis is often linked to inter-organizational network structure. Structure is a highly developed concept in inter-organizational relationships theory and typically includes elements such as membership, goals, specialization of tasks and division of labor, rules and regulations, standard operating procedures and designated authority relationships, coordinating mechanism and interorganizational agencies. Through stakeholders in collaborative processes generate a system for sustaining coincident values and establishing order within the domain [21]. According to Bryson et al. [10], there are three types of governance structure that influence the effectiveness of collaborations, such as self-governing structures, a lead organization, and network administrative organization. This latest literatures concerns and discusses specifically the interplay between multisector collaborative arrangements, between the public, private, and nonprofit sector. Based on the extant theoretical literatures, this paper categorizes the structure into power structure, organizational structure and technical structure.

3.2.1. Power structures. The growing use of collaborative methods of governance raises concerns about the relative power of participants in such processes and the potential for exclusion or domination of some parties [37]. Collaboration can be a way of advancing self-interested goals such as increasing power [22]. Many of these concerns are linked to power disparities among participating organizations and how power affects such issues as representation, participation, and voice [37]. The political party, such as CPC (Communist Party of China) can exercise powers through authority resources, and discursive legitimacy in collaborative governance processes. This article analyzes and assesses power structures and 
distribution and how power is used in collaborative governance processes, which will contribute to understand how power shapes collaborative processes and outcomes. Information in the public management setting is political power and is coveted by the politically powerful[9].Power imbalances between stakeholders are a commonly noted problem in collaborative governance [4,10,21].Gray argues that power differences among players influence their willingness to come to the table. If some stakeholders do not have the capacity, organization, status, or resources to participate, or to participate on an equal footing with other stakeholders, the collaborative governance process will be prone to manipulation by stronger actors [21].

3.2.2. Organizational structures. To fully exploit the benefits of ICT, public administration has to consider changing its organizational structure [15]. Collaborative management is a concept that describes the process of facilitating and operating in multiorganizational arrangements to solve problems that cannot be solved, or solved easily, by single organizations [1]. Most scholarship on collaborative governance emphasizes the emergence of networks or networked organizations as mechanism of improving public services delivery and policy making \& implementation. Networks have become a primary organizational setting for designing and implementing public policy, delivering public services, governing local and regional affairs. Scholars assert that practitioners and scholars of contemporary public administration need to treat network seriously [34]. Cross-sector collaborative networks are created when agencies agree to share information on an ongoing basis [16]. Designing cross-sector collaborative organizational structure enables a seamless and integrated governmental organization. The choice among types of organization governance structure is likely to influence cross-sector collaboration efficiency and effectiveness [36]. Cross-sector organizational arrangement provides a public forum through which the public managers and stakeholders involved in the process of building cross-sector collaborative egovernment resolve interagency differences and disputes, build agreement, design basic rules and regulations, which is critical for the procedural legitimacy and successful promotion of the cross-sector collaborative management in e-governance.

3.2.3. Technical structures. The technical structure constructs the primary work level of collaborative governance. The core of the technical structure is ICTs. Cross-sector collaboration and information integration became closely linked to the creative use of information technology (IT). Digital government means the use of information and communication technology, and particularly the Internet, as a tool to achieve better government [12]. The need for a transition from a single sector oriented to a multiple sector oriented public administration system has increased with the use of ICTs to support highly organizational structure and collaborative processes. Information resources sharing is a relatively new type of ICT initiative in collaborative e-Government; it involves building systems, instituting formal standards, and changing business processes to allow organizations to share data and information with many other organizations[12, 20]. These studies see cross-sector collaboration as resource-sharing arrangement based on the ICT structure. In a sense, cross-sector information sharing and integration efforts are politically, organizationally, and technologically challenging.

\subsection{Process of Collaboration and Integration}

The process components emphasizes six aspects: forging initial agreements, building leadership, building legitimacy, building trust, managing conflict, and planning [10]. Collaboration is a process in which autonomous actors interact through formal and informal negotiation, jointly creating rules and structures governing their relationships and ways to act or decide on the issues that brought them together; it is a process involving shared norms and mutually beneficial interactions [40]. Operating process of collaboration and integration is a process that includes a set of related activities designed to produce a particular outcome through collective actions. Structural characteristics of collaborative partnerships are related to both process and outcomes [7]. Governing structure and operating process often interact in cross-sector collaborations [10].

ICT also plays an important role in the operating process. In its broad sense, applying ICT to transform government structure and functions is to enhance egovernment interoperability and create collaborative egovernment [20], which promotes different agencies to develop cross-sector collaborative structure and work together to provide one-stop integrated and comprehensive services to citizens and businesses since government services are diverse and are offered by different agencies.

\subsection{Constraints on collaboration and integration}

Generally speaking, there often exists potential impediments particular to the government environment which could limit the attainment of collective and 
collaborative benefits, jeopardizing the project of collaborative e-Government [20]. Important differences exist among partnerships formed for system-level planning (identifying and defining system problems and solutions), administrative activities (involving resource transactions, such as sharing), or service delivery (such as client referral agreements)[8].Service delivery partnerships are more frequent and easier to sustain than those aimed at planning for systems change because system-level planning activities, like agenda setting in the public policy process, involve negotiating tough questions about the problem and creative solutions [8]. Similarly, Alter found that partnerships involving administrativelevel managers are more prone to conflict, whereas those coordinating service delivery among line staff experience greater cooperation [3].

Cross-sector collaborations and integration in OneStop Services Centers is based on political and administrative institutions. Political institutions define the framework within which politics take place [27]. Political institutions can constrain or motivate the use of information and ICTs, as a tool to achieve better government, and particularly information sharing. Many of these constraints are linked to power disparities among participating organizations, fragmentation of policy and motivations of cross-sector collaboration and information integration.

This article argues that there exist two main constraints on collaboration and integration, such as power disparities among partners of the collaborations and fragmentation of policy and motivations of crosssector collaboration. So the diagram includes two boxes for contingencies and constraints and arrows that go to both the process of collaboration and integration.

\subsection{Outcomes and Accountability}

It should be noted that much of the enthusiasm for cross-sector collaborations derives from beliefs and expectations about the positive effects of collaboration, rather than empirically demonstrated results. The point of creating and sustaining cross-sector collaborative ought to be the production of public value $[10,29]$ that cannot be created by single sectors alone. Public value in cross-sector collaborations is most likely created by making use of each sector's characteristic strengths while also finding ways to minimize, overcome, or compensate for each sector's characteristic weaknesses. Playing to the strengths of the different sectors seems logically linked to managing costs effectively and attending to diverse human needs and aspirations.

Accountability is a core issue in collaborative public management. Cross-sector collaborations are more likely to be successful when they have an accountability system that tracks inputs, processes, and outcomes; use a variety of methods for gathering, interpreting, and using data; and use a results management system that is built on strong relationships with key political and professional constituencies [10].

To enhance the efficiency and effectiveness of public service delivery and create more public values for the citizens through making the best use of the potential of ICT, cross-sector integration and collaboration is becoming an imperative for the public managers. For public managers, the challenge is to find feasible and effective strategies to reengineering governmental process and improve governance structures to strengthen the e-government interoperability and interconnectedness when the capacity for achieving joint activities and solving common problems is widely disperse, when few organizations accomplish their missions by acting alone, and when the fragmentation of service delivery damages the integration of service delivering, which is not citizen friendly.

\section{Methodology}

The research is conducted in compliance with a normative case study methodology. In the research process, we laid much emphasis on the diversity of data sources during the collection of evidence and materials. Current evidence for analysis include: responses to the open questionnaires distributed to several one-stop service centers in Chaoyang District; observation records of the project and part of the system usage records collected by one of the authors in the IT Office of Chaoyang District; records of field interviews conducted in IT Office and a one-stop service center in Gaobeidian, a subordinate area of Chaoyang District respectively; documents such as announcements, reports, and regulations provided by the government agency during the promotion of the "Quan-cheng-daiban” project. In addition, in order to secure a better construct validity of this study, we paid special attention to the diversity of data sources during the interviews. We interviewed the person in charge of this project in the IT Office, as well as three people in charge of relevant works in subordinate areas and endusers of this system, so as to construct an evidence triangulation to reduce the limitations caused by the choices of interviewees to the greatest extent [43].

In order to secure a better internal validity of the study, we conducted coding and scheme matching on the relevant qualitative research data collected. One problem that scholars in the IS field have long been faced is how the above-mentioned methods be effectively employed in examining and exploring the 
high-level theories in sociological research. In our research, we methodologically refer to the top-down and bottom-up combined approached proposed by Reimers and Jonston [39]. We first sorted the interview records and other raw materials and induced "rationales" from them, and then interpreted the case facts with the model deducted from the high-level theories.

\section{Case analysis}

Based on the method mentioned above, we encoded and analyzed the related material and several interview records derived from the implementing process of the "Quan-cheng-dai-ban” project and combed as follows according to Bryson's Framework:

\subsection{Initial Conditions}

The basal level of informatization in each subordinate area of Chaoyang district is uneven, and it can be generally divided into three circumstances: There is even lack of hardware and network environment needed for performing the "Quan-chengdai-ban" project in the service centers with the worst informatization foundation, where the competent authority of the district is required to allocate special funds to ensure the operation of the system. In the service centers with the best informatization foundation, however, informatization planning and information resource integration program have been voluntarily formulated in advance; the similar system has been developed, or the existing system has comprised similar functions, and as a result, the system is not upheld enthusiastically. Compared with the two cases above, the centers with the general basal level with respect to informatization possess the optimal environment for implementation of the system. In addition, the "Quan-cheng-dai-ban" mode is originated from the Huairou district of Beijing city. Objectively, the department defects at which the system is directed are more apparent in outer districts and counties. Although the Chaoyang district is located in ruralurban fringe zone, urbanization in this area advances faster, resulting in significant changes on the administration and key services of the regional service centers in Chaoyang district. To some extent, it weakens the pertinence of the "Quan-cheng-dai-ban" system to department defects and sows the seeds for several issues produced in the following operation of the system.

\subsection{Governing Structure}

The governance structure of the "Quan-cheng-daiban” project mainly relies on its administrative service center at the grass roots it is located.

Although the project was conducted in all subdistrict based on one information platform, in the interview, respondents said the usage of the system is not satisfied. The technological structure driven by ICT has been changed follow organizational process and power distribution.

Collaborative organization constitutes a hybrid organizational form generally should be based on agreement among different sectors. In Chinese local government, those important agreements generally are not list clearly, even in oral presentation. Therefore, top manager substitution could change the organization structure.

Researchers find that power is still a central concept in the resource dependency governance structure. With the current management system, the management responsibilities of the chief of the one-stop service centers focus on public resources and service attitude of the one-stop service centers, while the specific business of each department can only be supervised rather than being managed. More specifically, each officer at grass roots accepts the double leadership of the operating department to which they are subordinated and the regional offices where they work (instead of the one-stop service centers). Taking the fact that a majority of people consider the promotion in the operating departments is more promising into account, the former affects more significantly than the latter, which constitutes the reasons why the crosssector collaborative barriers are hardly smashed with the present governance structure.

\subsection{Process Components}

In terms of the implementing process of the "Quan-cheng-dai-ban" project, it is an IT project pursued dominantly by municipal leaders and carried out by each of district, following a top-down route. During the process of implementing the program, the governmental departments at all levels are allocated with related policy documents and therefore, leaders beyond all doubt pay great attention to the issue. The system depends on the existing administrative service center at grass roots, and the trust relationships have been built between them as staffs of the related departments have been working together in the center. However, the original intention of the "Quan-chengdai-ban" mode lies in catering to the general public. Therefore, rights and obligations of each department in the new operation flows have not been clearly defined all the time. Furthermore, the earlier stage of project is mainly boosted by IT office of the Chaoyang district, 
with an IT project as the positioning, and therefore, the use of the "Quan-cheng-dai-ban" system and its relationships with the original business and assessment of the departments fail to be definitely defined. It was until the eve of the 2008 Olympic Games when the Supervision Bureau of the district gets involved in the project by including the use of system and data integration into annual inspection requirements that the application of the system is transformed substantially. Another significant issue is that, although the participants at all levels are aware definitely the obstacle in propelling the "Quan-cheng-dai-ban" project lies in multidisciplinary conflict of interests, both the IT office and the Supervision Bureau fail to make an attempt for conflict management and coordination; on the contrary, both of them avoid the underlying conflicts and only attach importance to the outlet of each department, whether the officers at grass roots in the administrative service centers handle matter as requested, representing a suspicion of curing the symptoms, not the disease. Speaking of the planning, although the IT office has issued an explicit planning to integrate the "Quan-cheng-dai-ban" system and e-approving system in the future, staffs at all levels have no confidence in schedule of realizing the planning due to difficulties existed in the process and particularly, the officers at grass roots commonly consider it at a far distant date. Therefore, the "Quancheng-dai-ban" system is deemed as a temporary transitional system.

\subsection{Constraints on collaboration}

On the surface, the "Quan-cheng-dai-ban” project belongs to collaboration between service provision and administrative activity, however, its successful exercise in fact depends on sufficient sharing of the backstage information resources, which relates to systematic planning. Therefore, the project probably needs more cross-sector collaboration. Furthermore, power imbalance exerts the same critical influences and in fact, there are separate systems vertical from the national level for such mighty departments as public security and tax administration. No matter whether the safety risk exists, it is difficult for the regional governments to achieve substantial progress by attempting at integrating information resources, thereby resulting in that such integration is just the union of the underprivileged sectors and unstable, as those underprivileged sectors are positively looking for opportunities of acquiring power as the mighty sectors. There are also restrictions on current evaluation system. With respect to the monitoring system, when assessing the work performance of the district, it seems that the integration is beneficial for the district to gain praise, while when assessing the work performance of the department, the cooperative relations between the departments turn into the competitive ones. Such contradiction to some extent affects information resource integration.

\subsection{Outcomes and Accountability}

The “Quan-cheng-dai-ban” project aims at making citizens convenient, and there is no doubt about its public value, but in terms of the multiple order effects, the operation of the system fails to produce higher order effects. On the contrary, the obstacle in information resources integration makes the officers at grass roots complain that the achievement of the public convenience is at the expense of reducing their own work efficiency. It should be admitted that the "Quancheng-dai-ban” project has the mechanism of feedback and assessment and the information acquired from this channel facilitates the improvement of the system and workflow to a certain degree. However, the chain of current feedback mechanism is too long, bringing about low efficiency, which will possibly make no contribution to reversing the unfavorable situation of the present program.

\section{Concluding remarks}

In conclusion, the proposed factors, initial condition, structure, process, constraints, outcomes and accountability could help us find experiences and lessons from the local government information integration in the one-stop service center context. In on the one hand, the local government departments attempt to make efforts in achieving a higher level of collaboration by starting with service provision collaboration. On the other hand, a great number of limitations exist in operation and structure; while those limitations constitute exactly the reasons influencing the collaborative effects. The recognition of the above reasons will be helpful for researchers and practitioners to comprehend information resources integration and cross-sector collaboration more precisely, to adjust expectation for the target and time strategy so as to avoid entrapping into the vicious cycle of "admitting mistakes while brewing new mistakes".

With respect to the above situation, it is easy to figure out that no matter the "Quan Cheng Dai Ban" system or other attempts for information resources integration are hard to surmount the tremendous implementing hindrance caused by the barriers between higher and lower levels or between different departments and regions of the governmental powers. More extensively, two approaches may be effective for 
breaking through the information resources integration: (1) One is a top-down path. That is to say, only if we destroy the information resources barriers among vertical areas of the business based on the sufficient coordination of the all ministries and commissions, the administrative service centers at grass roots would potentially realize the real cross-system information resources sharing; (2)The another is a bottom-up path. If it is difficult to implement the top-down path at the present stage, the pilot in terms of administrative service resource integration at grass roots must be effectively combined with preparation of recombinant, making the administrative service centers become entity from the virtual pattern, and thus it is possible to make an attempt for the subsequent information resources integration. Therefore, the stable governance structure can be realized by focusing on the collaborative goal is essential for influencing collaborative performance. For the one-stop services center practices, if the local governments could endow the centers with functions and personnel authority as definite as those of the traditional department, they would have stronger capacity of integrating the administrative service resources dispersed in the different sectors.

\section{Acknowledgement}

This work was partly supported by the National Natural Science Foundation of China (71473143), the Beijing Social Science Foundation (15JGA008), the Tsinghua University Initiative Scientific Research Program (20131089260).

\section{References}

[1] Agranoff, R., \& McGuire, M. Collaborative Public Management: New Strategies for Local Governments. Washington, D.C.: Georgetown University Press, 2003.

[2] Alter, C. An Exploratory Study of Conflict and Coordination in Inter-organizational Service Delivery System. Academy of Management Journal, 1990, 33(3): 478-502.

[3] Alter, C., and Jerald H. Organizations Working Together. Newbury Park, CA: Sage, 1993.

[4] Ansell, C., \& Gash, A. Collaborative Governance in Theory and Practice. The Journal of Public Administration Research and Theory, 2008, 18(4): 543-571.

[5] Anninck, W., and Lucidarme, S. Pitfalls and Challenges for Trust and Effectiveness in Collaborative Networks, Public Management Review, 2014, 16(5): 733-760.
[6] Alford, J. The Multiple Facets of Co-Production: Building on the work of Elinor Ostrom. Public Management Review, 2014, 16(3): 299-316.

[7] Bidwell, R. D., \& Ryan C. M. Collaborative Partnership Design: The Implications of Organizational Affiliation for Watershed Partnerships. Society and Natural Resources, 2006, 19(9): 827-843.

[8] Bolland, J. M., \& Wilson, J. Three Faces of Integrative Coordination: A Model of Inter-organizational Relations in Community-Based Health and Human Services. Health Services Research, 1994, 29(3): 341-66.

[9] Bozenman, B., \& Straussman, J. D. Public Management Strategies: Guidelines for Managerial Effectiveness.

California, San Francisco: Jossey-Bass Inc., Publishers, 1990.

[10] Bryson, J. M., Crosby, B. C., \& Stone, M. M. The Design and Implementation of Cross-Sector Collaborations: Propositions from the Literature. Public Administration Review, 2006, 66(s1): 44-55.

[11] Clark, B. Y., Brudney, Jeffrey L. and Jang, S. Coproduction of Government Services and the New Information Technology: Investigating the Distributional Biases. Public Administration Review, 2013, 73 (5): 687-701.

[12] Dawes, S. S. The Evolution and Continuing Challenges of E-Governance. Public Administration Review,2008, 68(Special Issue): 86-102.

[13] Dormady, Noah C. The Political Economy of Collaborative Organization,Administration \& Society, 2013, 45(6): 748-772.

[14] Emerson, K, Nabatchi, T, Balogh, S. An Integrative Framework for Collaborative Governance, Journal of Public Administration Research and Theory,2012, 22(1):1-29.

[15]Ezz, I., Papazafeiropoulou, A., \& Serrano, A. Challenges of Inter-organizational Collaboration for Information Technology Adoption: Insights from a Governmental Financial Decision-Making Process in Egypt. Information Technology for Development, 2009, 15(3): 209-223.

[16] Fedorowicz, J., Gogan,J. L., \& Williams, C. B. A collaborative network for first responders: Lessons from the CapWIN case. Government Information Quarterly, 2007, 24: 785-807.

[17] Frederickson, H.G.Toward a Theory of the Public for Public Administration. Administration \& Society, 1991, 22(4): 395-417.

[18] Frederickson, H.G. The Repositioning of American Public Administration. Political Science and Politics, 1999, 32(4): 701-711.

[19] Gadot, E. V. Managing Collaboration in Public Administration: The promise of Alliance among Governance, 
Citizens, and Businesses. Westport, Connecticut: Praeger, 2003.

[20] Gil-Garcia, J. Ramon., Smith, C., \& Duchessi, P. Collaborative e-Government: impediments and benefits of information-sharing projects in the public sector. European Journal of Information Systems, 2007, 16(2): 121-133.

[21] Gray, B. Collaborating: Finding Common Ground for Multiparty Problems. San Francisco, California: Jossey-Bass Inc., Publishers. 1989.

[22] Huxham, C., and Siv V. Leadership in the Shaping and Implementation of Collaboration Agendas: How Th ings Happen in a (Not Quite) Joined-Up World. Academy of Management Journal, 2000, 43(6): 1159-75.

[23] Kapucu, N and Garayev, V. Designing, Managing, and Sustaining Functionally Collaborative Emergency Management Networks. American Review of Public Administration, 2013, 43(2): 312-330.

[24] Klijn, E.H. and Koppenjan, J. Governance Networks in the Public Sector. New York: Routledge, 2016.

[25] Lundin, Martin.. Explaining cooperation: How resource interdependence, goal congruence, and trust affect joint actions in policy implementation. Journal of Public Administration Research and Theory, 2007, 17(4): 651-672.

[26] Ma, L., Chung, J., \& Thorson, S. .E-government in China: Bringing economic development through administrative reform, Government Information Quarterly, 2005, 22(1): 20-37.

[27] March, James G, and Olsen, Johan P. Rediscovering Institutions: The Organizational Basis of Politics. New York, NY: The Free Press. 1989.

[28] McCaffrey, D. P., Sue R. F., and David W. H. The appeal and difficulties of participative systems. Organization Science, 1995, 6(6): 603-627.

[29]Moore, M. Creating public value: Strategic management in government. Cambridge, MA: Harvard University Press. 1995.

[30] O’Leary, R., Gazley, B., McGuire, M., \& Bingham, L. B. Public Managers in Collaboration. In The Collaborative Public Manager: New Ideas for the Twenty-First Century (O'Leary, R., 7 Bingham, L. B. ed.), Washington, D.C. Georgetown: University Press, 2009.

[31] Osbome, S. P., Radnor, Z. and Nasi, G. A New Theory for Public Service Management? Towards a (Public) Service Dominant Approach. American Review of Public Administration, 2013, 43(2): 135-158.

[32] Osbome, S. The New Public Governance? Public Management Review, 2006, 8(3): 377-387.
[33] Osbome, S. The New Public Governance? Emerging perspectives on the theory and practice of public governance. New York: Routledge. 2010.

[34] O'Toole, Laurence J. Treating Networks Seriously: Practical and Research-Based Agendas in Public Administration. Public Administration Review, 1997, 57(1): 41-52.

[35] Pestoff, V. Collective Action and the Sustainability of Co-Production. Public Management Review, 2014, 16(3): 383-401.

[36] Provan, K. G., \& Kenis, P. Modes of Network Governance and Implications for Public Network Management. In the Proceedings of the Eighth National Public Management Research Conference, Los Angeles, CA., 2005.

[37] Purdy, J. M. A Framework for Assessing Power in Collaborative Governance Processes. Public Administration Review, 2012, 72(3): 409-417.

[38] Radnor, Z., Osborne, S.P., Kinder,T. and Mutton, J. Operationalizing co-production in public services delivery: The contribution of service blueprinting. Public Management Review, 2014, 16(3): 402-423.

[39] Reimers, K., \& Johnston, R. B. The Use of an Explicitly Theory-Driven Data Coding Method for High-Level Theory Testing in IOIS, In the Proceedings of the 28th International Conference on Information Systems (ICIS), Paris,

France.2008.

[40] Thomson, A. M., \& Perry, J. L. Collaboration Processes: Inside the Black Box. Public Administration Review, 2006, 66(s1): 20-32.

[41] Wang, L., \& Ngok, K. Social policy between plan and market: Xiagang (off-duty employment) and the policy of the re-employment service centers in China. Social Policy \& Administration, 2006, 40(1): 158-173.

[42] Wong, C. Rebuilding Government for the 21st Century: Can China Incrementally Reform the Public Sector? China Quarterly, 2009, 200: 929-952.

[43] Yin, R. K. Case Study Research: Design and Methods. Sage Publications, Thousand Oaks, CA, 2003.

[44] Zhang, N., Guo, X., \& Chen, G. Why Adoption and Use Behavior of IT/IS Cannot Last? Two Studies in China. Information Systems Frontiers, 2011. 13(3): 381-395.

[45]Zhang, T. From intercity competition to collaborative planning: The case of the Yangtze River Delta region of China. Urban Affairs Review, 2006, 42(1): 26-56. 